\title{
Postoperative Crohn's Disease and Relapse Risk Factors: A Single Centre Experience
}

\section{Srdjan Markovic ${ }^{1,2 *}$, Slobodan Sreckovic ${ }^{1}$, Branimir Zogovic $^{3}$ and Petar Svorcan $^{1,2}$}

${ }^{1}$ Department of Gastroenterology, Clinical Center Zvezdara, Belgrade, Serbia

${ }^{2}$ School of Medicine, University of Belgrade, Serbia

${ }^{3}$ Department of Surgery, Royal Prince Alfred Hospital, Camperdown, NSW Australia

*Corresponding Author: Srdjan Markovic, Department of Gastroenterology, University Hospital Medical Center "Zvezdara”, School of Medicine, University of

Belgrade, Serbia.
Received: January 15, 2021

Published: February 17, 2021

(C) All rights are reserved by Markovic

Srdjan.,et al.

\section{Abstract}

Introduction and Aim: Surgical intervention is an unavoidable companion for majority of patients with Crohn's Disease (CD). In this study we determine with Crohn's Disease (CD).

Methods: 50 CD patients with at least one surgical resection were assessed retrospectively. Patients underwent clinical (CDAI) and endoscopic (Rutgeerts) assessments at the Department of Gastroenterology and Hepatology, University Hospital "Zvezdara” on average 36 months after their operation. Age at diagnosis, gender, smoking status, duration of CD before resection, presence of perianal disease, colonic involvement, length of resected segment, type of anastomosis, concomitant immunomodulators and biologics (anti-TNF) were reviewed as potential risk factors for clinical and endoscopic recurrence. Data were analysed using univariate and multivariate logistic regression analyses.

Results: $74 \%$ of patients had clinical remission and $40 \%$ of patients had endoscopic remission. Patients in clinical remission were significantly younger than patients that relapsed. Termino-lateral anastomosis resulted in higher remission rates, $66 \%$ compared to $25 \%$ of patients with termino-terminal anastomosis. Anti-TNF therapy was crucial for maintenance of clinical remission. Older age at diagnosis and extensive small bowel resection were risk factors for endoscopic recurrence based on multivariate logistic regression analysis.

Conclusion: Older age at the time of diagnosis, lack of biologics postoperatively, latero-lateral or termino-terminal anastomosis as well as extensive resection were high risk factors for relapse in postoperative CD patients.

Keywords: Anastomosis; Anti-TNF Therapy; Crohn's Disease; Postoperative Course; Resection; Risk Factors

\section{Abbreviations}

CD: Crohn's Disease; IBD: Inflammatory Bowel Disease; NA: Not Applicable

\section{Introduction}

Around $80 \%$ of patients with Crohn's Disease (CD) will need surgery at some stage and $70 \%$ of these patients will need more than one surgical intervention [1]. Clinical and endoscopic relapses are common and are estimated at $10-38 \%$ and $35-85 \%$ in the first year, respectively [2].

Identifying CD patients at risk of relapse in the first 36 months post operation is a great challenge. Risk factors can be classified

Citation: Markovic Srdjan., et al. "Postoperative Crohn's Disease and Relapse Risk Factors: A Single Centre Experience". Acta Scientific Gastrointestinal Disorders 4.3 (2021): 19-26. 
into: patient related (i.e. gender, smoking, family history of inflammatory bowel disease), disease related (disease duration, extensiveness and localisation, perianal disease, penetrant disease, NOD2/CARD 15/IBD1 status, presence of granuloma and myenteric plexitis, previous resection, elevated levels of TGF- $\beta$ ) and operation related (i.e. extensive resection of $>50 \mathrm{~cm}$, marginal resection, stricturoplasty, need for transfusion, and postoperative complications) $[3,4]$. The Rutgeerts score is most commonly used tool to assess endoscopic relapses, typically one year postoperatively (Table 1) $[5,6]$.

\begin{tabular}{|c|c|c|}
\hline Scale & Lesion & $\begin{array}{l}\text { Assessment of } \\
\text { clinical relapse }\end{array}$ \\
\hline i0 & No lesions & \multirow{2}{*}{$\begin{array}{c}<10 \% \text { for } 10 \\
\text { years }\end{array}$} \\
\hline i1 & $<5$ aphthous ulceration & \\
\hline i2 & $\begin{array}{c}>5 \text { aphthous lesions on IC } \\
\text { anastomosis }\end{array}$ & $20 \%$ for 5 years \\
\hline i3 & Diffuse aphthous ileitis & \multirow{2}{*}{$\begin{array}{l}50-100 \% \text { during } \\
\text { five years with } \\
\text { increased } \\
\text { possibility of } \\
\text { reoperation }\end{array}$} \\
\hline i4 & $\begin{array}{l}\text { Diffuse inflammation with large } \\
\text { ulceration and narrowing of } \\
\text { anastomosis }\end{array}$ & \\
\hline
\end{tabular}

Table 1: Rutgeerts`score.

A number of medications can be used for postoperative prophylaxis depending on the risk of relapse as well as the pharmacokinetic panel of the medication [7]. Mesalazines, imidazole antibiotics $[8,9]$, thiopurines and tumour necrosis factor (TNF) blockers $[10,11]$ are the medications of choice.

The main goal of the study was to identify postoperative risk factors for clinical and endoscopic relapses in CD patients. The secondary goal was to assess the role of immunosuppressive and biological therapy on maintaining remission. Identifying these risk factors may be used to stratify high from low relapse risk patients and monitor the high-risk patients closely as they may need more aggressive treatment. In this study, we compare our results with published European guides.

\section{Materials and Methods}

50 patients with $\mathrm{CD}$ who underwent at least one surgical resection in the 2009-2015 period were examined retrospectively. All patients were treated at the Department of Gastroenterology and
Hepatology of the University Clinical Center "Zvezdara”, Belgrade. $\mathrm{CD}$ diagnosis was determined based on clinical, laboratory, radiological and histological criteria [12]. The Montreal classification was used to determine CD localisation and behaviour [13].

Inclusion criteria for this study were: 1. Age 18- 65 years; 2. patients with at least one small bowel resection, and/or colon resection; 3. A postoperative immunosuppressive protocol: a. azathioprine (AZA, $2-2.5 \mathrm{mg} / \mathrm{kg}$ ) for up to three months after surgery, b. methotrexate (MTX, 25mg intramuscular or subcutaneously) weekly for 12 weeks, then decreased to $15 \mathrm{mg}$ weekly followed by mandatory folic acid $(10 \mathrm{mg} / 24 \mathrm{~h})$ for three days; c. biological therapy, i.e. TNF- $\alpha$ blockers: adalimumab in the standard induction protocol $1160 \mathrm{mg}$ subcutaneously in the first week, $80 \mathrm{mg}$ subcutaneously in the second week, $40 \mathrm{mg}$ subcutaneously in the third week), then according to the protocol of maintenance ( $40 \mathrm{mg}$ fortnightly), or infliximab in the standard induction protocol $(5 \mathrm{mg} / \mathrm{kg}$ at 0,2 and 6 weeks) and thereafter continuation with maintenance ( $5 \mathrm{mg} / \mathrm{kg}$ every eight weeks), $\mathrm{d}$. combined therapy: adalimumab + azathioprine/methotrexate or infliximab + azathioprine/methotrexate, e. patients without maintenance therapy or f. mesalazine (3g/daily).

Clinical remission and relapse were evaluated based on the value of Crohn's Disease Activity Index (CDAI): a. Remission was defined as CDAI <150; b. Relapse was defined as a CDAI $>150$. Endoscopic activity was assessed by total colonoscopy and terminal ileoscopy based on Rutgeerts score (RS, i.e., 0-4; table 1): a. endoscopic remission for RS values of i0 and i1. b. Endoscopic relapse for RS values of i2, i3 and i4.

We analysed patients demographics, disease progression (age at diagnosis, first operation, consecutive resections), smoking status, Montreal Classification (age at diagnosis, location of disease, illness behaviour), family history, type of preoperative and postoperative therapy, number of resections, type of resection and the length of the resected segment.

\section{Statistical analysis}

SPSS Statistics 20 (Chicago, IL, USA) was used for statistical analysis. Descriptive statistics - for parametric variables arithmetic mean and standard deviation or median (according to the type of distribution data), while non-parametric characteristics 
frequency percentages were used. Student T-test/Mann - Whitney or Kruskal-Walis test (based on type data distribution) were used to check for differences between means variables or median c. $\chi 2$ and Fisher's test were used to determine differences in frequency. Univariate analysis and multivariate binary logistic regression (methods Backward stepwise) was used to analyse the risk factors for clinical and endoscopic, postoperative relapse.

The study was approved by the local ethics committee.

\section{Results and Discussion}

Table 2 shows the demographic characteristics of $50 \mathrm{CD}$ patients with at least one surgical resection. The average age of patients was 43 years with a relatively equal gender distribution ( $46 \%$ women, $54 \%$ men). $36 \%$ of patients were smokers, while $10 \%$ had positive family history for IBD. The average age at diagnosis was 31 and the disease on average lasted 11 years. The most common complications were stricture (64\%), penetration (28\%) and inflammation (8\%). Perianal disease was found in a third of the patients.

\begin{tabular}{|l|c|}
\hline \multicolumn{1}{|c|}{ Demographics } & N = 50 \\
\hline Age (years), mean \pm SD & $43 \pm 11$ \\
\hline Females, n (\%) & $23(46 \%)$ \\
\hline Disease duration (years), Med+IQR & $11 \pm 10$ \\
\hline Positive IBD family history, n (\%) & $5(10 \%)$ \\
\hline Smokers & $18(36 \%)$ \\
\hline Age at diagnosis (years), Med+IQR & $30.5 \pm 18.0$ \\
\hline Montreal Age at diagnosis - A, n (\%) & \\
A1\&A2, & $37(74 \%)$ \\
A3 & $13(26 \%)$ \\
\hline Montreal disease localization - L, n (\%) & \\
L1 & $24(48 \%)$ \\
L3 & $26(52 \%)$ \\
\hline Montreal behaviour - B, n (\%) & \\
B1 - non-stricturing, non-penetrating & $4(8 \%)$ \\
B2 - stricturing & $32(64 \%)$ \\
B3 - Penetrating & $14(28 \%)$ \\
\hline Perianal disease present, n (\%) & $17(34 \%)$ \\
\hline Immunomodulators (IMD); $n$ (\% of 50 & $33(66 \%)$ \\
patients) & $28(85 \%)$ \\
Azathioprine (AZA) & $5(15 \%)$ \\
Methotrexate (MTX) & $912 \%)$ \\
\hline Combined therapy (Anti-TNF $\alpha+A Z A / M T X) ;$ \\
$n$ (\% of 50 patients) & $(42 \%)$ \\
Infliximab (IFX) & 12 of 21 \\
Adalimumab (ADA) & $(58 \%)$ \\
\hline
\end{tabular}

\begin{tabular}{|l|c|}
\hline Other therapies, n (\%): & $17(34 \%)$ \\
Mesalamine & $7(41 \%)$ \\
Metronidazole & 0 \\
Without therapy (\% of other) & $10(59 \%)$ \\
\hline
\end{tabular}

Table 2: Demographic characteristics of patients with CD.

33 out of 50 patients $(66 \%)$ were treated with immunomodulator (IMD) therapy - azathioprine or methotrexate, 21(42\%) out of which were treated with a combined biological agent protocol (adalimumab or infliximab). 14\% (7/50) of patients were treated with mesalazine $(3 \mathrm{~g} / \mathrm{d})$, while $20 \%(10 / 50)$ of patients did not receive any treatment. The number and type of surgical interventions are shown in table $3.72 \%$ of patients had only one surgical resection, $24 \%$ had two, while only two patients (4\%) were operated three times. Median time from the last resection was 1.5 years (IQR 5), while the median time between resections was 5.5 years (IQR 8). $56 \%$ of patients had termino-lateral (TL) anastomosis, $32 \%$ termino-terminal (TT) and $12 \%$ had latero-lateral (LL) anastomosis. Resected segments varied greatly in length $(10-150 \mathrm{~cm})$.

\begin{tabular}{|l|c|}
\hline Resections, $\mathrm{n}(\%)$ & $36(72 \%)$ \\
One & $12(24 \%)$ \\
Two & $2(4 \%)$ \\
Three & $1.5 \pm 5(0-20)$ \\
\hline Time from last resection, Med + IQR & $3 \pm 7(0-10)$ \\
First resection & $2.5 \pm 9(0-20)$ \\
Second resection & $5.5 \pm 8.0(0-13)$ \\
Time between resections & $45 \pm 41(10-150)$ \\
\hline Resected segments length (cm), Med & \\
+ IQR & $35(70 \%)$ \\
\hline Resected segment length (cm), n (\%): & $15(30 \%)$ \\
$>50$ cm & \\
$<50$ cm & $28(56 \%)$ \\
\hline Anastomosis type, $\mathrm{n}(\%):$ & $16(32 \%)$ \\
Termino-Lateral (TL) & $6(12 \%)$ \\
Termino-Terminal (TT) & \\
Latero-Lateral (LL) & \\
\hline
\end{tabular}

Table 3: Number and type of surgical resections, length of the resected segment in 50 resected patients with $C D$.

Tables 4-6 show the risk of relapse depending on the number/ type of resection, the length of resection, the clinical properties of 
patients with one or more resections and the postoperative status. $74 \%$ of patients were in clinical remission, in contrast to the $40 \%$ of patients in endoscopic remission (table 5). We identified four favourable factors: single resection (patient had significantly shorter disease duration; table 4, P $<0.01$; OR 5,76, CI 1.7-24.4), younger age ( $41 \pm 2$ years vs. $49 \pm 3$ years for relapsed patients, $\mathrm{P}<$ 0.05 , table 6$)$, type of anastomosis ( $66 \%$ of patients with TL anastomosis were in clinical remission compared to $25 \%$ in relapse; $\mathrm{P}$ $<0.05$; OR 3.84; CI 1:39 to 10:58) and anti-TNF $\alpha$ therapy (clinical remission maintained even after 3 years; $\mathrm{P}<0.05$, CI 3:58; $1: 22$ to 10:42). Multivariate logistic regression analysis revealed older age at diagnosis and extensive small bowel resection as risk factors for endoscopic recurrence. While, the ileum was most commonly affected (55\% patients with any L1 were in clinical remission, while $25 \%$ were in the deterioration of the 3 years after operations), it was not statistically significant compared to other sites $(\mathrm{P}=0.06$; OR 3.67, CI 0.86-15.87).

\begin{tabular}{|c|c|c|c|c|}
\hline Characteristics & $\begin{array}{c}\text { One } \\
\text { resection }\end{array}$ & $\begin{array}{l}\text { Two or more } \\
\text { resections }\end{array}$ & Odds ratio & $\begin{array}{c}P \\
\text { value }\end{array}$ \\
\hline Age (years) & $41.8 \pm 11.0$ & $45.9 \pm 12.4$ & NA & 0.26 \\
\hline $\begin{array}{l}\text { Disease } \\
\text { duration } \\
(<10 y) ; \\
\text { n } \%\end{array}$ & $22(61 \%)$ & $3(21 \%)$ & $\begin{array}{c}5.8 \\
\text { CI 1.4-24.4 }\end{array}$ & $0.01^{*}$ \\
\hline Females; n \% & $16(44 \%)$ & $7(50 \%)$ & $\begin{array}{c}1.3 \\
\text { CI } 0.4-4.3\end{array}$ & 0.72 \\
\hline Smokers, n \% & $12(33 \%)$ & $6(43 \%)$ & $\begin{array}{c}1.50 \\
\text { CI } 0.4-5.3 \\
\end{array}$ & 0.5 \\
\hline $\begin{array}{l}\text { Age at diagnosis } \\
(\mathrm{A} 1, \mathrm{~A} 2), \mathrm{n} \%\end{array}$ & $24(67 \%)$ & $13(92 \%)$ & $\begin{array}{c}6.5 \\
\text { CI } 0.7-5.6 \\
\end{array}$ & 0.06 \\
\hline $\begin{array}{l}\text { Montreal L1; } \\
\text { n \% }\end{array}$ & $16(44 \%)$ & $8(57 \%)$ & $\begin{array}{c}0.6 \\
\text { CI } 0.2-2.1 \\
\end{array}$ & 0.4 \\
\hline $\begin{array}{l}\text { Montreal B2; } \\
\text { n \% }\end{array}$ & $22(36 \%)$ & $10(71 \%)$ & $\begin{array}{c}1.6 \\
\text { CI } 0.4-6.1 \\
\end{array}$ & 0.5 \\
\hline $\begin{array}{l}\text { Perianal } \\
\text { disease; n \% }\end{array}$ & $13(36 \%)$ & $4(29 \%)$ & $\begin{array}{c}1.4 \\
\text { CI } 0.4-5.4\end{array}$ & 0.6 \\
\hline $\begin{array}{l}\text { Immunosup- } \\
\text { pressive } \\
\text { therapy; n \% }\end{array}$ & $25(70 \%)$ & $8(57 \%)$ & $\begin{array}{c}1.7 \\
\text { CI } 0.4-6.1\end{array}$ & 0.41 \\
\hline $\begin{array}{l}\text { IT duration; } \\
\text { (Median } \pm \text { IQR) }\end{array}$ & $2 \pm 5$ & $4.5 \pm 6$ & NA & 0.40 \\
\hline
\end{tabular}

\begin{tabular}{|l|c|c|c|c|}
\hline $\begin{array}{l}\text { Endoscopic } \\
\text { remission; } \\
\text { n, \% }\end{array}$ & $15(42 \%)$ & $5(38)$ & $\begin{array}{c}1.3 \\
\text { CI } 0.4-4.6\end{array}$ & 0.70 \\
\hline $\begin{array}{l}\text { Clinical } \\
\text { remission }\end{array}$ & $28(77 \%)$ & $10(71 \%)$ & $\begin{array}{c}1.4 \\
\text { CI } 0.3-5.7\end{array}$ & 0.63 \\
\hline $\begin{array}{l}\text { Termino-lateral } \\
\text { anastomosis }\end{array}$ & $22(61 \%)$ & $6(42 \%)$ & & 0.34 \\
\hline
\end{tabular}

Table 4: Clinical characteristics of two groups of patients with one or more resections.

\begin{tabular}{|l|c|}
\hline \multicolumn{1}{|c|}{ Postoperative status } & N = 50 \\
\hline $\begin{array}{l}\text { Clinical remission (CDAI <150); n, } \\
(\%)\end{array}$ & $38(74 \%)$ \\
\hline Clinical relapse (CDAI >150), n, (\%) & $12(26 \%)$ \\
\hline Endoscopic remission (i0, i1), n, (\%) & $20(40 \%)$ \\
\hline Endoscopic relapse (i2, i3, i4), n, (\%) & $30(60 \%)$ \\
\hline Rutgeerts' score i0 & $9(18 \%)$ \\
\hline Rutgeerts' score i1 & $11(22 \%)$ \\
\hline Rutgeerts' score i2 & $8(16 \%)$ \\
\hline Rutgeerts' score i3 & $15(30 \%)$ \\
\hline Rutgeerts' score i4 & $7(14 \%)$ \\
\hline
\end{tabular}

Table 5: Postoperative status after 36 months (Median follow-up of the last operation).

\begin{tabular}{|l|c|c|c|c|}
\hline Characteristics & $\begin{array}{c}\text { Clinical } \\
\text { remission }\end{array}$ & $\begin{array}{c}\text { Clinical } \\
\text { relapse }\end{array}$ & Odds ratio & $\begin{array}{c}\text { P } \\
\text { value }\end{array}$ \\
\hline Age (mean \pm SE) & $41 \pm 2$ & $49 \pm 3$ & NA & $0.024^{*}$ \\
\hline $\begin{array}{l}\text { Age at diagnosis } \\
\text { (median } \pm \text { IQR) }\end{array}$ & $30 \pm 17$ & $37 \pm 14$ & NA & 0.21 \\
\hline $\begin{array}{l}\text { Disease duration } \\
\text { (median } \pm \text { IQR) }\end{array}$ & $11 \pm 11$ & $15 \pm 13$ & NA & 0.83 \\
\hline $\begin{array}{l}\text { Resections }>1 ; \\
\text { n \% }\end{array}$ & $28(74 \%)$ & $8(66 \%)$ & 1.40 & 0.64 \\
\hline $\begin{array}{l}\text { T-L anastomosis; } \\
\text { n \% }\end{array}$ & $25(66 \%)$ & $3(25 \%)$ & $\begin{array}{c}\text { CI } \\
1.3910 .58\end{array}$ & $\mathbf{0 . 0 3 *}$ \\
\hline
\end{tabular}




\begin{tabular}{|c|c|c|c|c|}
\hline $\begin{array}{l}\text { Resected } \\
\text { segment <50cm; } \\
\text { n } \%\end{array}$ & $26(68 \%)$ & $9(75 \%)$ & $\begin{array}{c}1.38 \\
\text { CI } 0.31 \\
-6.06\end{array}$ & 0.66 \\
\hline $\begin{array}{l}\text { Non-smokers; } \\
\text { n \% }\end{array}$ & $25(66 \%)$ & $7(58 \%)$ & $\begin{array}{c}1.37 \\
\text { CI } 0.36-5.18\end{array}$ & 0.64 \\
\hline $\begin{array}{l}\text { Age at diagnosis } \\
(\mathrm{A} 1, \mathrm{~A} 2) \mathrm{n} \%\end{array}$ & $30(79 \%)$ & $7(58 \%)$ & $\begin{array}{c}2.69 \\
\text { CI } 0.66- \\
10.72 \\
\end{array}$ & 0.156 \\
\hline $\begin{array}{l}\text { L1 Montreal } \\
\text { category }\end{array}$ & $21(55 \%)$ & $3(25 \%)$ & $\begin{array}{c}3.67 \\
\text { CI } 0.86- \\
15.87\end{array}$ & 0.06 \\
\hline $\begin{array}{l}\text { B2/B Montreal } \\
\text { category }\end{array}$ & $25(66 \%)$ & $7(58 \%)$ & $\begin{array}{c}1.37 \\
\text { CI } 0.36-5.18\end{array}$ & 0.64 \\
\hline Perianal disease & $14(37 \%)$ & $3(25 \%)$ & $\begin{array}{c}0.89 \\
\text { CI } 0.65-1.19 \\
\end{array}$ & 0.450 \\
\hline $\begin{array}{l}\text { Immunosup- } \\
\text { pressive therapy } \\
\text { (IT), n\% }\end{array}$ & $27(71 \%)$ & $6(50 \%)$ & $\begin{array}{c}2.45 \\
\text { CI } 0.64-9.25\end{array}$ & 0.18 \\
\hline $\begin{array}{l}\text { IT duration in } \\
\text { years } \\
(\text { median } \pm \mathrm{IQR})\end{array}$ & $3 \pm 5$ & $2 \pm 4$ & NA & 0.73 \\
\hline $\begin{array}{l}\text { Biological } \\
\text { therapy (BT), } \\
\text { n \% }\end{array}$ & $20(52 \%)$ & $1(8 \%)$ & $\begin{array}{c}1.26 \\
\text { CI } 1.44-10.0\end{array}$ & $0.007 *$ \\
\hline $\begin{array}{l}\text { BT duration in } \\
\text { years } \\
\text { (median } \pm \mathrm{IQR} \text { ) }\end{array}$ & $1 \pm 1$ & $1 \pm 1$ & NA & 0.99 \\
\hline $\begin{array}{l}\text { Endoscopic } \\
\text { remission } \\
\text { n \% }\end{array}$ & $20(52 \%)$ & $0(0 \%)$ & $\begin{array}{c}1.66 \\
\text { CI } 1.24-2.32\end{array}$ & $0.001 *$ \\
\hline
\end{tabular}

Table 6: Differences in clinical characteristics of patients in clinical relapse or remission, 36 months (median) from surgery.

Immunosuppressive and biological therapies have improved the outcomes for postoperative patients with Crohn's Disease [4]. The European Crohn's and Colitis Organisation (ECCO) recommends a minimum of two years therapy with azathioprine and methotrexate for postoperative patients [14], particularly since azathioprine is good in the prevention of clinical and endoscopic relapses [15]. Biologic therapy with anti-TNF $\alpha$ is superior to immunosuppressive therapy and is considered most effective in preventing postoperative relapse $[4,16]$. While infliximab is superior to azathioprine and monotherapy with infliximab alone can achieve high rates in endoscopic remissions $[4,5,16]$, ECCO recommends supplemental treatment with thiopurines for patients with high risk for postoperative relapse [17]. In our study, 21 (42\%) patients were treated with biological therapy in combination with azathioprine or methotrexate protocol (table 2). 20 patients achieved clinical remission 36 months after surgery as a result of biological therapy, while only one patient had clinical deterioration ( $\mathrm{P}<0.05)$. Univariate and multivariate analyses suggested biological therapy as a significant predictor of clinical remission, but not for achieving endoscopic remission. Several reasons arise: first, the criteria for the introduction of biological therapies are heterogeneous. In particular, while ECCO recognises previous surgery, smoking and penetrating phenotype as risk factors, the second European evidence-based Consensus did not follow suit [3]. Secondly, inadequate early endoscopic surveillance and treatment can affect the postoperative results at the 36-month mark. Finally, when patients in this study had their operations six years ago, there were no specific postoperative follow-up guides established and implemented in any major IBD European centre. The POCER study defined the protocols of postoperative follow-up for patients with Crohn's Disease and emphasised endoscopy as the pivotal tool for postoperative follow-up $[4,18]$. A 1990 prospective cohort study showed that patients with minimal endoscopic lesions (i0 and i1) had a very favorable postoperative clinical course [4], in contrast to patients with RS> i1. An Italian prospective cohort study demonstrated relapse in $48 \%$ of studied patients, with $38 \%$ of the patients relapsing only after six months [19]. The high rates of clinical and endoscopic remission in at 36 months follow up in our study may be due to the fact that $42 \%$ of patients were receiving biological therapy concurrently.

There are conflicting reports about the preventative efficacy when thiopurines are combined with imidazoles, specifically metronidazole. Some authors have demonstrated greater preventative effect [20], while others have shown endoscopic deterioration as high as $44 \%$ and $82 \%$ in the first and fifth follow up year, respectively [21]. In our study, biological therapy was essential in achieving remission, and neither immunosuppressive therapy nor the length of IMD therapy had an effect on this. The finding cannot not be generalised due to the small number of participants along with lack of pre-selection criteria.

The 2010 ECCO guide stressed the role of smoking, previous intestinal resection (including appendectomy), extensive intestinal 
resection, penetrating phenotype and perianal disease as risk factors [3]. In our study, with 35\% of smokers in endoscopic remission and $37 \%$ of non-smokers with endoscopic relapse, smoking was not identified as a risk factor for prediction of clinical or endoscopic relapse. The small cohort and the short follow up period may explain why smoking was not a risk factor in our study.

Age at diagnosis is not a clearly defined risk factor for relapse and surgical interventions as studies are conflicting [4,22]. Our study did not show that younger age at diagnosis is a risk factor for relapse. In fact, our patients in clinical and endoscopic remission were significantly younger than the group with clinical relapse. This may be explained by the fact that older patients who have a long disease history may have a poorer response to biological therapy.

The impact of disease location was investigated in previous studies with varied results [6]. In a European study, the upper segments of the digestive tract (L4) were identified as a risk factor for postoperative relapse [23]. Only one study identified the colon (L2) as a predictive factor for clinical relapse however the study had a small number of participants [24]. In our study, relapses favored the ileocolic region but the difference was not significant relapses (L3; $75 \%$ vs $45 \%$ ). Penetrating phenotype is an independent factor for postoperative relapse [3,4]. A meta-analysis of 13 studies showed that perianal fistula is a risk factor for clinical and endoscopic relapse (HR 1.5, 95\% CI: 1.16-1.93) [25]. In our cohort, B3 phenotype was found in $50 \%$ of patients with an endoscopic deterioration compared to $20 \%$ who were in endoscopic remission. In the postoperative period, endoscopic relapse develops proximal to the anastomosis. Although it is believed that the causes are multifactorial, it is assumed that faecal stream plays an important role [26]. In addition to this, luminal size may contribute to disease relapse as it may be a ground for obstruction or secondary bacterial contamination. Because of this, many authors proposed "side to side" anastomosis over "end to end" anastomosis. Meta-analysis showed that "side to side" anastomosis was associated with a lower degree of postoperative relapse [27]. In our cohort, most patients had termino-lateral (TL) anastomosis and $66 \%$ of these patients were in clinical remission $(\mathrm{P}<0.05)$. Multivariate analysis suggested TL anastomosis as an independent factor associated with the clinical remission. However, the type of anastomosis did not affect the occurrence of endoscopic relapse.

\section{Conclusion}

In summary, our results show that after a median of 36 months, $60 \%$ of patients had endoscopic relapse, while significantly smaller number, $26 \%$ were in clinical deterioration. These results are surprisingly positive compared to other studies, probably due to the fact that almost half the cohort was treated with TNF blockers postoperatively. Older age, termino-terminal, latero-lateral anastomosis and the absence of biological therapies were identified as risk factors for postoperative relapse. Our study is limited by its retrospective design and the small to moderate number of patients. Patients were selected from the 2009 - 2015 electronic database and complete documentation in electronic form exists only for 2015. Despite the limitations, we believe that this study contributes to everyday clinical practice.

\section{Conflict of Interest}

The authors declare no conflicts of interest.

\section{Bibliography}

1. Lewis Robert T and David J Maron. "Efficacy and Complications of Surgery for Crohn's Disease". Gastroenterology and Hepatology 6.9 (2010): 587-596.

2. Buisson A., et al. "Review Article: The Natural History of Postoperative Crohn's Disease Recurrence". Alimentary Pharmacology and Therapeutics 35.6 (2012): 625-633.

3. Van Assche G., et al. "The Second European Evidence-Based Consensus on the Diagnosis and Management of Crohn's Disease: Special Situations". Journal of Crohn's and Colitis 4.1 (2010): 63-101.

4. De Cruz P., et al. “Crohn's Disease Management after Intestinal Resection: A Randomised Trial”. Lancet 385.9976 (2015): 1406-1417.

5. Rutgeerts P., et al. "Predictability of the Postoperative Course of Crohn's Disease". Gastroenterology 99.4 (1990): 956-963.

6. De Cruz P., et al. "Postoperative Recurrent Luminal Crohn's Disease: A Systematic Review". Inflammatory Bowel Disease 18.4 (2012): 758-777. 
7. Michetti P. “Postsurgical Prophylaxis in Crohn's Disease: Which Patients, Which Agents?” Digestive Disease 33 (2015): 78-81.

8. Rutgeerts P., et al. "Natural History of Recurrent Crohn's Disease at the Ileocolonic Anastomosis after Curative Surgery". Gut 25.6 (1984): 665-672.

9. Landsend E., et al. "Long-Term Outcome after Intestinal Resection for Crohn's Disease”. Scandinavian Journal of Gastroenterology 41.10 (2006): 1204-1208.

10. Gjuladin-Hellon T., et al. "Azathioprine and 6-Mercaptopurine for Maintenance of Surgically-Induced Remission in Crohn's Disease". Cochrane Database System Review 8.8 (2019): Cd010233.

11. Regueiro M., et al. “Infliximab Prevents Crohn's Disease Recurrence after Ileal Resection". Gastroenterology 136.2 (2009): 441-450.e1; quiz 716.

12. Dignass A., et al. "The Second European Evidence-Based Consensus on the Diagnosis and Management of Crohn's Disease: Current Management". Journal of Crohn's and Colitis 4.1 (2010): 28-62.

13. Satsangi J., et al. "The Montreal Classification of Inflammatory Bowel Disease: Controversies, Consensus, and Implications". Gut 55.6 (2006): 749-753.

14. Gomollón F., et al. "3rd European Evidence-Based Consensus on the Diagnosis and Management of Crohn's Disease 2016: Part 1: Diagnosis and Medical Management". Journal of Crohn's and Colitis 11.1 (2017): 3-25.

15. Peyrin-Biroulet, L., et al. "Azathioprine and 6-Mercaptopurine for the Prevention of Postoperative Recurrence in Crohn's Disease: A Meta-Analysis". American Journal of Gastroenterology 104.8 (2009): 2089-2096.

16. Carla-Moreau A., et al. "Prevention and Treatment of Postoperative Crohn's Disease Recurrence with Anti-Tnf Therapy: A Meta-Analysis of Controlled Trials". Digestive and Liver Disease 47.3 (2015): 191-196.
17. Pittet V., et al. "When Do We Dare to Stop Biological or Immunomodulatory Therapy for Crohn's Disease? Results of a Multidisciplinary European Expert Panel". Journal of Crohn's and Colitis 7.10 (2013): 820-826.

18. Rutgeerts P., et al. "Controlled Trial of Metronidazole Treatment for Prevention of Crohn's Recurrence after Ileal Resection". Gastroenterology 108.6 (1995): 1617-1621.

19. Orlando A., et al. "Early Post-Operative Endoscopic Recurrence in Crohn's Disease Patients: Data from an Italian Group for the Study of Inflammatory Bowel Disease (Ig-Ibd) Study on a Large Prospective Multicenter Cohort". Journal of Crohn's and Colitis 8.10 (2014): 1217-1221.

20. D’Haens G R., et al. "Therapy of Metronidazole with Azathioprine to Prevent Postoperative Recurrence of Crohn's Disease: A Controlled Randomized Trial”. Gastroenterology 135.4 (2008): 1123-1129.

21. Domènech E., et al. "Impact of Azathioprine on the Prevention of Postoperative Crohn's Disease Recurrence: Results of a Prospective, Observational, Long-Term Follow-up Study". Inflammatory Bowel Disease 14.4 (2008): 508-513.

22. Beaugerie L., et al. "Predictors of Crohn's Disease". Gastroenterology 130.3 (2006): 650-656.

23. Wolters F L., et al. "Phenotype at Diagnosis Predicts Recurrence Rates in Crohn's Disease". Gut 55.8 (2006): 1124-1130.

24. Sahmoud T., et al. "Identifying Patients with a High Risk of Relapse in Quiescent Crohn's Disease. The Getaid Group. The Groupe D'etudes Thérapeutiques Des Affections Inflammatoires Digestives". Gut 37.6 (1995): 811-818.

25. Simillis C., et al. "A Meta-Analysis Comparing Conventional End-to-End Anastomosis Vs. Other Anastomotic Configurations after Resection in Crohn's Disease". Diseases of the Colon and Rectum 50.10 (2007): 1674-1687.

26. Caprilli R., et al. "Prognostic Factors for Postoperative Recurrence of Crohn's Disease. Gruppo Italiano Per Lo Studio Del Colon E Del Retto (Gisc)". Diseases of the Colon and Rectum 39.3 (1996): 335-341. 
27. Simillis C., et al. "A Meta-Analysis Comparing Incidence of Recurrence and Indication for Reoperation after Surgery for Perforating Versus Nonperforating Crohn's Disease". American Journal of Gastroenterology 103.1 (2008): 196-205.

\section{Assets from publication with us}

- Prompt Acknowledgement after receiving the article

- Thorough Double blinded peer review

- Rapid Publication

- Issue of Publication Certificate

- High visibility of your Published work

Website: www.actascientific.com/

Submit Article: www.actascientific.com/submission.php

Email us: editor@actascientific.com

Contact us: +919182824667 